\title{
Brain natriuretic peptide release in patients with aortic stenosis: Resting and exercise echocardiographic determinants
}

\author{
Christine Henri a,b,1, Julien Magne a, Raluca Dulgheru ${ }^{a}$, Saloua Laaraibi a , Damien Voilliot ${ }^{\text {a }}$, Seisyou Kou ${ }^{\text {a }}$, \\ Luc Pierard ${ }^{\mathrm{a}, *}$, Patrizio Lancellotti ${ }^{\mathrm{a}, *}$ \\ a University of Liège Hospital, GIGA Cardiovascular Sciences, Department of Cardiology, Heart Valve Clinic, CHU Sart Tilman, Liège, Belgium \\ b University of Montreal, Department of Medicine, Montreal Heart Institute, Canada
}

\section{A R T I C L E I N F O}

Article history:

Received 14 January 2014

Accepted 18 January 2014

Available online 25 January 2014

\section{Keywords:}

Aortic valve

B-type natriuretic peptide

Exercise Doppler echocardiography

Aortic stenosis (AS) is the most common valvular heart disease in western countries [1]. Recent series reported that early surgery, i.e. aortic valve replacement (AVR) in asymptomatic patients and preserved left ventricular (LV) function, was associated with improved clinical outcomes [2,3]. Although AVR is safe and widely performed, the rates of both operative mortality and valve-related complications cannot be overlooked. The risk-benefit ratio of early strategy should be carefully evaluated and the decision-making could be refined by quantitative and reliable parameters. In this regard, the recently updated ESC guidelines suggest the usefulness of B-type natriuretic peptide (BNP) level measurement [4]. The aim of this study was to identify resting and exercise echocardiographic determinants of BNP level in asymptomatic patients with AS and preserved LV function.

We prospectively included 61 asymptomatic patients with at least moderate AS (aortic valve area $<1.5 \mathrm{~cm}^{2}$ ) and preserved LV ejection fraction $(>50 \%$ ) that were referred to our Heart Valve Clinic to perform resting and exercise Doppler echocardiography with concomitant BNP level measurement. The study protocol conforms to the ethical guidelines of the 1975 Declaration of Helsinki as reflected in a priori approval by the institution's human research committee and all patients gave written informed consent.

Patients were divided into 2 groups according to BNP level median $(66 \mathrm{pg} / \mathrm{mL})$. All patients presented at least a moderate AS $\left(1.0 \pm 0.3 \mathrm{~cm}^{2}\right.$; range: $\left.0.4-1.5 \mathrm{~cm}^{2}\right)$ and preserved $\mathrm{LV}$ ejection fraction (69 $\pm 7 \%$; range: $55-81 \%$ ). Mean age of the population was $70 \pm 13$ (range: $31-87$ ) years old and a significant correlation between age and BNP levels was found $(\mathrm{r}=0.40 ; \mathrm{p}=0.001)$. The distribution of BNP levels was $104 \pm 142 \mathrm{pg} / \mathrm{mL}$; median: 66; range: $5-700 \mathrm{pg} / \mathrm{mL}$. Patients in the high BNP level group were significantly older $(p<0.001)$, more often in atrial fibrillation $(p<0.001)$ or with hypertension $(p=0.048)$. There were no other significant differences regarding clinical characteristics.

Patients in the high BNP level group had significant higher indexed left atrial area $(\mathrm{p}=0.017)$ and $\mathrm{E} / \mathrm{e}^{\prime}$ ratio $(\mathrm{p}=0.001)$. There was no significant difference in AS severity and LV mass, volumes and function between groups (Table 1). Significant correlations were found between BNP levels and indexed left atrial area $(\mathrm{r}=0.346 ; \mathrm{p}=0.008), \mathrm{E} / \mathrm{A}$ ratio $(\mathrm{r}=0.344$; $\mathrm{p}=0.009)$ and $\mathrm{E} / \mathrm{e}^{\prime}$ ratio $(\mathrm{r}=0.584 ; \mathrm{p}<0.001$, Fig. $1 \mathrm{~b})$. After adjustment

\footnotetext{
* Corresponding authors at: Department of Cardiology, University Hospital, Université de Liège, CHU du Sart Tilman, 4000 Liège, Belgium. Tel.: + 324366 71 94; fax: +3243667195.

E-mail addresses: lpierard@chu.ulg.ac.be (L. Pierard),plancellotti@chu.ulg.ac.be (P. Lancellotti).

${ }^{1}$ This author takes responsibility for all aspects of the reliability and freedom from bias of the data presented and their discussed interpretation.
}

for age, indexed aortic valve area, LV global longitudinal strain and left atrial area, multivariable analysis identified $\mathrm{E} / \mathrm{e}^{\prime}(\beta=18.2 \pm 2.9$; $\mathrm{p}<0.001)$ and LV end-diastolic volume $(\beta=-2.1 \pm 0.7 ; \mathrm{p}=0.006)$ as independent resting predictors of BNP level.

Patients in the high BNP level group had significant higher exercise $\mathrm{E} / \mathrm{e}^{\prime}$ ratio $(\mathrm{p}=0.018)$ and lower $\mathrm{LV}$ global longitudinal strain $(\mathrm{p}=0.020)$. There was no difference in AS severity, LV stroke volume and ejection fraction between groups (Table 1). Significant correlations were found between BNP levels and exercise indexed aortic valve area $(\mathrm{r}=-0.324 ; \mathrm{p}=0.028), \mathrm{E} / \mathrm{e}^{\prime}$ ratio $(\mathrm{r}=0.543 ; \mathrm{p}<0.001$; Fig. 1c) and LV global longitudinal strain $(r=-0.491 ; p=0.002$; Fig. 1d). After adjustment for age and indexed aortic valve area, multivariable analysis identified $\mathrm{E} / \mathrm{e}^{\prime}(\beta=14.4 \pm 5.6 ; \mathrm{p}=0.015)$ and LV global longitudinal strain $(\beta=-9.7 \pm 3.6 ; p=0.011)$ as independent exercise determinants of BNP level.

This study shows that, in asymptomatic patients with preserved LV function and at least moderate AS, the BNP level is determined by LV end-diastolic volume, both resting and exercise estimated LV filling pressure and exercise LV global longitudinal strain, suggesting the presence of both subclinical LV diastolic and systolic dysfunction.

In the natural history of AS, the chronic increase in afterload is compensated by LV remodeling and concentric hypertrophy maintaining patients free of symptoms. However, at a later stage, LV hypertrophy may be no longer sufficient to compensate the afterload and increase in LV wall stress and filling pressure may occur resulting in symptoms and poor outcome. The $\mathrm{E} / \mathrm{e}^{\prime}$ ratio is recognized as a noninvasive measurement of LV filling pressure in patients with AS $[5,6]$ and the BNP activation is known to be a good surrogate marker of the occurrence of symptoms [6,7]. Consistently, our results have shown that the main determinant of BNP level is the estimated LV filing pressure using $\mathrm{E} / \mathrm{e}^{\prime}$ ratio. In a cohort of 135 patients with $\mathrm{AS}$, several indices of LV diastolic function were associated with BNP level, such as the E/A ratio, the $\mathrm{E} / \mathrm{e}^{\prime}$ ratio and the left atrial area, regardless of the symptomatic status [8]. Those data are concordant with our findings. However, to the best of our knowledge, we are the first to validate those parameters as independent determinants of BNP level in a cohort of "truly" asymptomatic patients with AS and preserved LV function.

Even in patients with severe AS, LV ejection fraction may remain normal during a long time. However, LV global longitudinal strain has been shown to reveal intrinsic myocardial dysfunction in those patients. In fact, a decrease in global longitudinal strain was superior to standard LV ejection fraction measurement in predicting symptoms, exercise tolerance and outcome $[9,10]$. In the presence of severe AS, the afterload mismatch and the increase in LV filling pressure may dramatically limit the recruitment of longitudinal myocardial reserve during exercise. Very few data are available relative to exerciseinduced changes in LV longitudinal function and none have evaluated their association with BNP release. In our study, we have demonstrated that exercise global longitudinal strain was independently associated with BNP level.

Compared to previous studies, AS severity parameters did not emerge as independent predictors of BNP level and those correlations were probably weakened by the analysis of more powerful predictors. Also, indexed LV mass was not significantly related to BNP level. This illustrates that LV afterload rather than the amount of LV hypertrophy 
Table 1

Echocardiographic data according to BNP level.

\begin{tabular}{|c|c|c|c|c|}
\hline & Whole cohort $\mathrm{n}=61$ & Low BNP group $n=32,52 \%$ & High BNP group $n=29,48 \%$ & p-Value \\
\hline \multicolumn{5}{|l|}{ Resting parameters } \\
\hline \multicolumn{5}{|l|}{ AS severity } \\
\hline Peak velocity, m/s & $3.7 \pm 0.7$ & $3.6 \pm 0.5$ & $3.8 \pm 0.8$ & 0.369 \\
\hline Mean pressure gradient, $\mathrm{mm} \mathrm{Hg}$ & $37 \pm 14$ & $34 \pm 10$ & $40 \pm 17$ & 0.130 \\
\hline Indexed valve area, $\mathrm{cm}^{2} / \mathrm{m}^{2}$ & $0.53 \pm 0.13$ & $0.55 \pm 0.11$ & $0.52 \pm 0.16$ & 0.350 \\
\hline \multicolumn{5}{|l|}{ LV geometry and function } \\
\hline Indexed mass, $\mathrm{g} / \mathrm{m}^{2}$ & $88 \pm 26$ & $83 \pm 26$ & $93 \pm 24$ & 0.146 \\
\hline Indexed end-diastolic volume, $\mathrm{mL} / \mathrm{m}^{2}$ & $44 \pm 12$ & $46 \pm 14$ & $42 \pm 9$ & 0.286 \\
\hline Indexed end-systolic volume, $\mathrm{mL} / \mathrm{m}^{2}$ & $14 \pm 6$ & $15 \pm 7$ & $13 \pm 4$ & 0.139 \\
\hline Indexed stroke volume, $\mathrm{mL} / \mathrm{m}^{2}$ & $45 \pm 9$ & $44 \pm 8$ & $46 \pm 10$ & 0.536 \\
\hline Ejection fraction, \% & $69 \pm 7$ & $68 \pm 6$ & $70 \pm 7$ & 0.246 \\
\hline E/A ratio & $0.90 \pm 0.35$ & $0.84 \pm 0.30$ & $0.97 \pm 0.40$ & 0.185 \\
\hline $\mathrm{E} / \mathrm{e}^{\prime}$ ratio & $11 \pm 4$ & $9 \pm 3$ & $13 \pm 5$ & 0.001 \\
\hline Global longitudinal strain, \% & $-20 \pm 3$ & $-20 \pm 3$ & $-19 \pm 3$ & 0.200 \\
\hline Indexed left atrial area, $\mathrm{cm}^{2} / \mathrm{m}^{2}$ & $9.6 \pm 2.4$ & $8.9 \pm 2.1$ & $10.4 \pm 2.6$ & 0.017 \\
\hline \multicolumn{5}{|l|}{ Exercise parameters } \\
\hline \multicolumn{5}{|l|}{ AS severity } \\
\hline Peak velocity, m/s & $4.2 \pm 0.8$ & $4.1 \pm 0.6$ & $4.2 \pm 0.9$ & 0.620 \\
\hline Mean pressure gradient, $\mathrm{mm} \mathrm{Hg}$ & $48 \pm 20$ & $44 \pm 16$ & $52 \pm 25$ & 0.167 \\
\hline Indexed valve area, $\mathrm{cm}^{2} / \mathrm{m}^{2}$ & $0.57 \pm 0.13$ & $0.58 \pm 0.11$ & $0.55 \pm 0.15$ & 0.324 \\
\hline \multicolumn{5}{|l|}{ LV geometry and function } \\
\hline Indexed stroke volume, $\mathrm{mL} / \mathrm{m}^{2}$ & $48 \pm 12$ & $46 \pm 9$ & $50 \pm 15$ & 0.221 \\
\hline Ejection fraction, \% & $72 \pm 6$ & $73 \pm 5$ & $72 \pm 7$ & 0.883 \\
\hline $\mathrm{E} / \mathrm{e}^{\prime}$ ratio & $12 \pm 4$ & $11 \pm 3$ & $14 \pm 5$ & 0.018 \\
\hline Global longitudinal strain, \% & $-21 \pm 3$ & $-23 \pm 3$ & $-20 \pm 3$ & 0.020 \\
\hline
\end{tabular}

AS indicates aortic stenosis and LV indicates left ventricular.

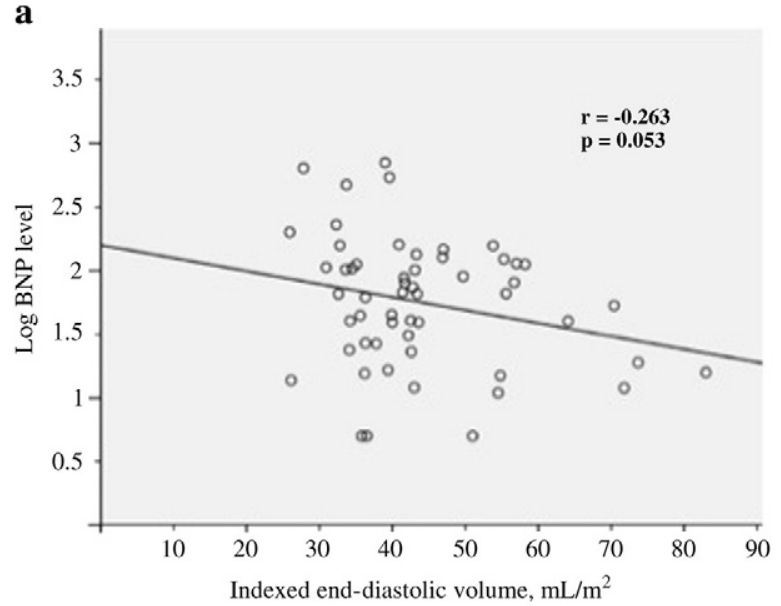

c

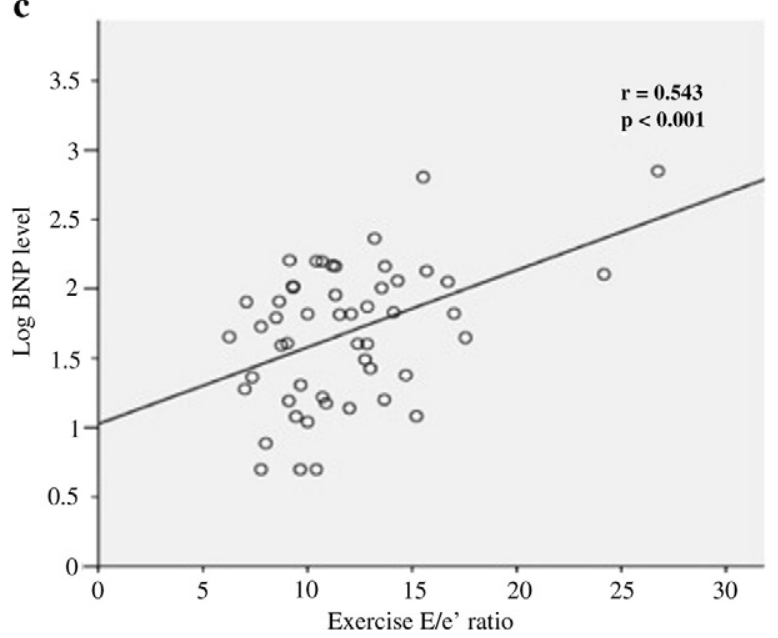

b

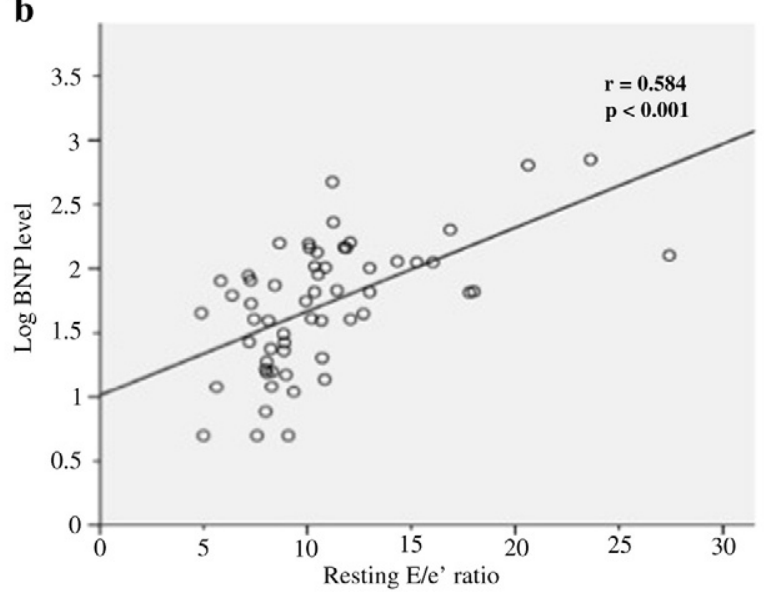

d

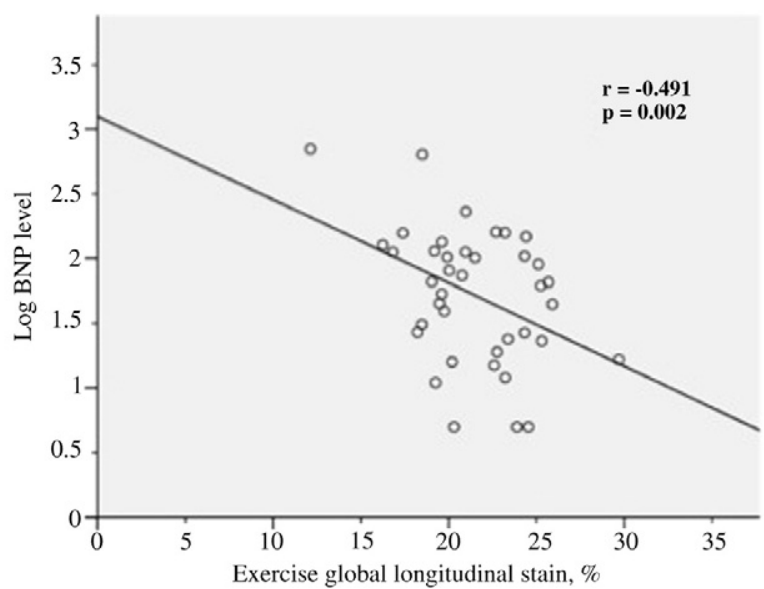

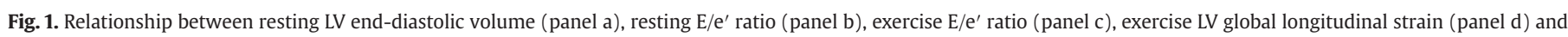
BNP level. 
may contribute: (1) to the elevation of LV wall stress and filling pressure, and (2) to the impairment of the LV longitudinal function by reducing coronary flow reserve.

In asymptomatic patients with moderate to severe AS and preserved LV ejection fraction, BNP release is mainly determined by LV end-diastolic volume, LV filling pressure estimation (diastolic burden) and exercise LV longitudinal strain (subclinical LV dysfunction). Further studies are needed to clarify the role of those determinants in risk stratification of asymptomatic patients with AS.

P.L. This work was supported by the Belgian National Fund for Scientific Research (F.R.S-FNRS T.0028.14).

C.H. received grants from the Montreal Heart Institute Foundation (Bourse du Bal du Cœur), and the Department of Medicine of the University of Montreal and the Association des Cardiologues du Québec.

\section{References}

[1] Iung B, Baron G, Butchart EG, et al. A prospective survey of patients with valvular heart disease in Europe: the euro heart survey on valvular heart disease. Eur Heart J 2003;24:1231-43.
[2] Brown ML, Pellikka PA, Schaff HV, et al. The benefits of early valve replacement in asymptomatic patients with severe aortic stenosis. J Thorac Cardiovasc Surg 2008;135:308-15

[3] Kang DH, Park SJ, Rim JH, et al. Early surgery versus conventional treatment in asymptomatic very severe aortic stenosis. Circulation 2010;121:1502-9.

[4] Vahanian A, Alfieri O, Andreotti F, et al. Guidelines on the management of valvular heart disease (version 2012). Joint Task Force on the Management of Valvular Heart Disease of the European Society of Cardiology, European Association for Cardio-Thoracic Surgery. Eur Heart J 2012;33:2451-96.

[5] Dalsgaard M, Kjaergaard J, Pecini R, et al. Left ventricular filling pressure estimation at rest and during exercise in patients with severe aortic valve stenosis: comparison of echocardiographic and invasive measurements. J Am Soc Echocardiogr 2009;22:343-9.

[6] Lancellotti P, Moonen M, Magne J, et al. Prognostic effect of long-axis left ventricular dysfunction and b-type natriuretic peptide levels in asymptomatic aortic stenosis. Am J Cardiol 2010;105:383-8.

[7] Bergler-Klein J, Klaar U, Heger M, et al. Natriuretic peptides predict symptom-free survival and postoperative outcome in severe aortic stenosis. Circulation 2004;109:2302-8.

[8] Marechaux S, Hattabi M, Juthier F, et al. Clinical and echocardiographic correlates of plasma b-type natriuretic peptide levels in patients with aortic valve stenosis and normal left ventricular ejection fraction. Echocardiography 2011;28:695-702.

[9] Lafitte S, Perlant M, Reant P, et al. Impact of impaired myocardial deformations on exercise tolerance and prognosis in patients with asymptomatic aortic stenosis. Eur J Echocardiogr 2009;10:414-9.

[10] Lancellotti P, Donal E, Magne J, et al. Risk stratification in asymptomatic moderate to severe aortic stenosis: the importance of the valvular, arterial and ventricular interplay. Heart 2010;96:1364-71.

\title{
Functional deficiency of natural killer cells in acute coronary syndrome is related to ineffective degranulation ${ }^{\text {ts }}$
}

\author{
Young-Joon Hong a,1, Young-Nan Cho b,1, Tae-Jong Kim ${ }^{\text {b }}$, Hye-Mi Jin ${ }^{\text {b }}$, Moon-Ju Kim ${ }^{\text {b }}$, Hyun-Ju Jung ${ }^{\text {, }}$, \\ Jeong-Hwa Kang ${ }^{\mathrm{b}}$, Sung-Ji Lee ${ }^{\mathrm{b}}$, Ki-Jeong Park ${ }^{\mathrm{b}}$, Nacksung Kim ${ }^{\mathrm{c}}$, Seung-Jung Kee ${ }^{\mathrm{d}, *}$, Yong-Wook Park ${ }^{\mathrm{b}, * *}$ \\ a Department of Cardiology, Chonnam National University Medical School and Hospital, Gwangju, Republic of Korea \\ b Department of Rheumatology, Chonnam National University Medical School and Hospital, Gwangiu, Republic of Korea \\ c Department of Pharmacology, Chonnam National University Medical School, Gwangju, Republic of Korea \\ d Department of Laboratory Medicine, Chonnam National University Medical School and Hospital, Gwangju, Republic of Korea
}

\section{A R T I C L E I N F O}

\section{Article history:}

Received 15 January 2014

Accepted 18 January 2014

Available online 25 January 2014

\section{Keywords:}

Acute coronary syndrome

Natural killer cell

CD107a

Dysfunction

Degranulation

It has been suggested that atherosclerosis involves cross talk between innate and adaptive immunity [1]. Natural killer (NK) cells principally contribute to innate immunity and adaptive immune

\footnotetext{
is Funding: This study was supported by grants from the National Research Foundation of Korea Grant funded by the Korean Government (grants 2011-0008875 2011-0011332, and 2013R1A2A2A01067956).

* Correspondence to: S.-J. Kee, Department of Laboratory Medicine, Chonnam National University Medical School and Hospital, 42 Jebong-ro, Dong-gu, Gwangju 501-757, Republic of Korea. Tel.: + 8262 2205343; fax: + 82622226592.

** Correspondence to: Y.-W. Park, Department of Rheumatology, Chonnam National University Medical School and Hospital, 42 Jebong-ro, Dong-gu, Gwangju 501-757, Republic of Korea. Tel.: + 8262 2206275; fax: + 82622226592 .

E-mail addresses: sjkee@chonnam.ac.kr (S.-J. Kee), parkyw@jnu.ac.kr (Y.-W. Park)

${ }^{1} \mathrm{YJH}$ and YNC contributed equally to this work.
}

responses by killing target cells or by prompting the productions of various cytokines and chemokines [2]. Due to these properties, NK cells play significant roles in the control of microbial infections [3]. Several human studies have shown that NK cell activity is depressed in patients with coronary artery disease (CAD) [4,5]. However, the mechanism of NK cell dysfunction in CAD remains unclear. The core of toxic granules in NK cells is surrounded by a lipid bilayer that contains Fas ligand and LAMPs [6]. As degranulation occurs, secretory lysosomes are released, and LAMP-1 (known as CD107a) is transported to the cellular surface. Thus, the cell surface expression of lysosomal-associated membrane protein-1 (LAMP-1 or CD107a) has been described as a sensitive marker for NK cell degranulation and cytotoxicity [7]. Accordingly, the aim of this study was to evaluate NK cell level and function in CAD, and to investigate changes in NK cell degranulation.

The study cohort included 59 healthy controls (HCs), 66 patients with chronic stable angina (CSA), and 121 patients with acute coronary syndrome (ACS). The subjects with no symptoms of CAD and with normal routine laboratory test results were enrolled as a healthy control group. However, no coronary angiogram was performed in the control group. NK cells were identified phenotypically as CD3-CD45+CD56 + cells by flow cytometry [8]. Circulating NK cell numbers and cytotoxicities of peripheral blood mononuclear cells (PBMCs) and NK cells against K562 cells were assayed by flow cytometry as previously described [8]. The degranulation of NK cells in response to K562 cells was determined by flow cytometry as 